\title{
A new Reactive Atom Plasma Technology (RAPT) for precision machining: the etching of $\mathrm{ULE}^{\circledR}$ surfaces
}

\author{
Dr Carlo Fanara ${ }^{1,2}$, Prof. Paul Shore ${ }^{2}$, Prof. John R Nicholls ${ }^{1}$, Mr. Nicholas Lyford ${ }^{3}$, \\ Dr Jude Kelley ${ }^{3}$, Dr Jeff Carr ${ }^{3}$ and Mr. Phil Sommer ${ }^{3}$
}

${ }^{1}$ National High Temperature Surface Engineering Centre, Building 57, Cranfield University, MK430AL Cranfield, United Kingdom, c.fanara@ cranfield.ac.uk

${ }^{2}$ Manufacturing Systems Department, Cranfield University, MK43 0AL Cranfield, Bedfordshire, United Kingdom

${ }^{3}$ RAPT Industries, 6252 Preston Avenue, Livermore, CA 94551-0234, United States of America

\begin{abstract}
Results on reactive atom plasma etching performed on ULE ${ }^{\circledR}$ (Corning Ultra Low Expansion) glass samples at atmospheric pressure are presented for the first time. A reactive atomic plasma technology $\left(\right.$ RAPT $\left.^{\circledR}\right)$, has been developed by RAPT Industries and employed for the finishing of optical surfaces. An atmospheric pressure argon inductively coupled plasma (ICP) excites a reactive gas injected through its centre. The plume of hot neutral excited species reacts at the substrate yielding controlled and repeatable trenches. In the case of ULE a material removal (up to $0.55 \mathrm{~mm}^{3} / \mathrm{s}$ ) is obtained without pre-heating the samples. Among the factors influencing the results, an increase in gas concentration at the same power does not change the sample temperature, indicating that thermo-chemical effects do not influence the removal rates. Due to the plasma constructive constrains, increasing the gas concentration is more practical and of wider effect than increasing the power. The benefits of the process are illustrated and the extension of the technology to large optical surfaces discussed.
\end{abstract}

PACS: 52.77.Bn, 52.80.Pi, 42.70, 78.68, 81.20

\section{Introduction}

As part of the Basic Technology programme run jointly by UCL and Cranfield University ${ }^{[1]}$, a reactive atomic plasma technology $\left(\right.$ RAPT $\left.^{\circledR}\right)$, which emerged from the US National Ignition Facility project at the Lawrence Livermore National Laboratory, has been developed by RAPT Inc (US). This new technology was patented in 2002 and employed for the finishing of surfaces of various materials of optical interest ${ }^{[2]}$.

In agreement with existing work atom etching at atmospheric pressure using fluorine rich gases may achieve substantial removal rates provided the removed materials is released in volatile fluorinated form ${ }^{[3]}$. In the course of the last decades, several studies on plasma etching have been performed but in these works the requirement of small size patterns indicated needs for lower operating pressure ${ }^{[3-5]}$. For example, from one would conclude that as $\mathrm{NF}_{3}$ present undercuts in argon mixture this specie would not be suitable for the etching of Si based compounds (table 2 in $\left.{ }^{[3}\right]$ ). However, etching is considered only at low pressure, well below 1 Torr. The chemistry of $\mathrm{NF}_{3}$ etching at atmospheric pressure appears quite undeveloped. Moreover, from table 2 in the 
same work $\left({ }^{[3]}\right)$ it would appear that the chemical etching due to the fluorine species is isotropic whereas we will show that the results on material removal obtained in this work clearly contradict this hypothesis. The reaction path of the fluorine may be quite distinct not only because of the pressure but also because of the originating mixture $\left(\mathrm{NF}_{3}\right)$ and of the surface temperature which is one of the major variables at play ${ }^{[3]}$. For example in the case of $\mathrm{SiO}_{2}$ there is experimental evidence of loss of selectivity of $\mathrm{Si}$ versus $\mathrm{SiO}_{2}$ induced by surface heating ${ }^{[3]}$.

A large process parameter window is accessible to ULE optics which is advantageous for large and curved optics ${ }^{[6]}$. Moreover, high etch selectivity may be required when etching coatings relative to the substrate optics, which may be difficult in multiphase and multi-component material like Zerodur $\left(\mathrm{SiO}_{2}, 35\right.$ to $75 \% ; \mathrm{Al}_{2} \mathrm{O}_{3} \sim 20$ to $50 \%$, Ti, $\mathrm{Zr}, \mathrm{Li}, \mathrm{Mg}, \mathrm{P}$ oxides ${ }^{[7]}$ ), which could lead to surface roughening ${ }^{[8]}$. With respect to the roughness increase upon material removal (coating) indications on small increase are reported, when the method used was RIE on multi-layered systems ${ }^{[8]}$. So far however, we were not able to find published work on ICP chemical etching at atmospheric pressure on none of the typical materials of interest in optics, nor specifically on ULE.

Other processes may be employed for the manufacturing and figuring of optical surfaces for large mirrors, Ion Beam Figuring (IBF, also known as Ion-beam polishing or ion-etching ${ }^{[9]}$ ) is the most promising in terms of speed of process and quality of the finishes. With IBF one may achieve typical ion beam sputter removal of $0.1-20 \mu \mathrm{m}^{3} / \mathrm{s}$ using commercial FIB systems, depending on the material to be figured ${ }^{[11][10]}$ and references [27-29] therein,). For comparison, mechanical processes, like the polishing on the Zeeko IRP200 machine, may reach volumetric removal rates of $0.105 \mathrm{~mm}^{3} /$ minute $^{[12]}$. The only other known plasma process at atmospheric pressure is owned by Nikon Corporation and even if the substrate composition is not indicated, volumetric removal rates of up to $0.019 \mathrm{~mm}^{3} / \mathrm{s}$ are reported $\left(\sim 70 \mathrm{~mm}^{3} /\right.$ hour $\left.^{[13]}\right)$. Even if possible roughness increase of the bombarded material can be avoided ${ }^{[14]}$, FIB requires large and expensive high vacuum chambers and high grade clean rooms.

In the RAPT ${ }^{\circledR}$ process the use of argon shielding makes the latter unnecessary. An atmospheric pressure argon inductively coupled plasma (ICP) excites a reactive gas which is injected through its centre (see figure 1).

The argon plasma acts as a thermal reservoir and excites the admitted species. These are conveyed by the plasma flow to the substrate where they react, yielding controlled and repeatable trenches which show pseudo-gaussian profiles. Naturally, the choice of the active species and its concentration depends on the material to be treated and on the desired removal rate. Under these conditions the mean free path for ions in argon are at the micrometer scale and in the system described in this work, indications exist that charged particle densities are negligible a few $\mathrm{mm}$ outwards the plasma nozzle ${ }^{[2]}$ so that among the mechanisms indicated in literature, the purely chemical mode dominates ${ }^{[3,4]}$. 


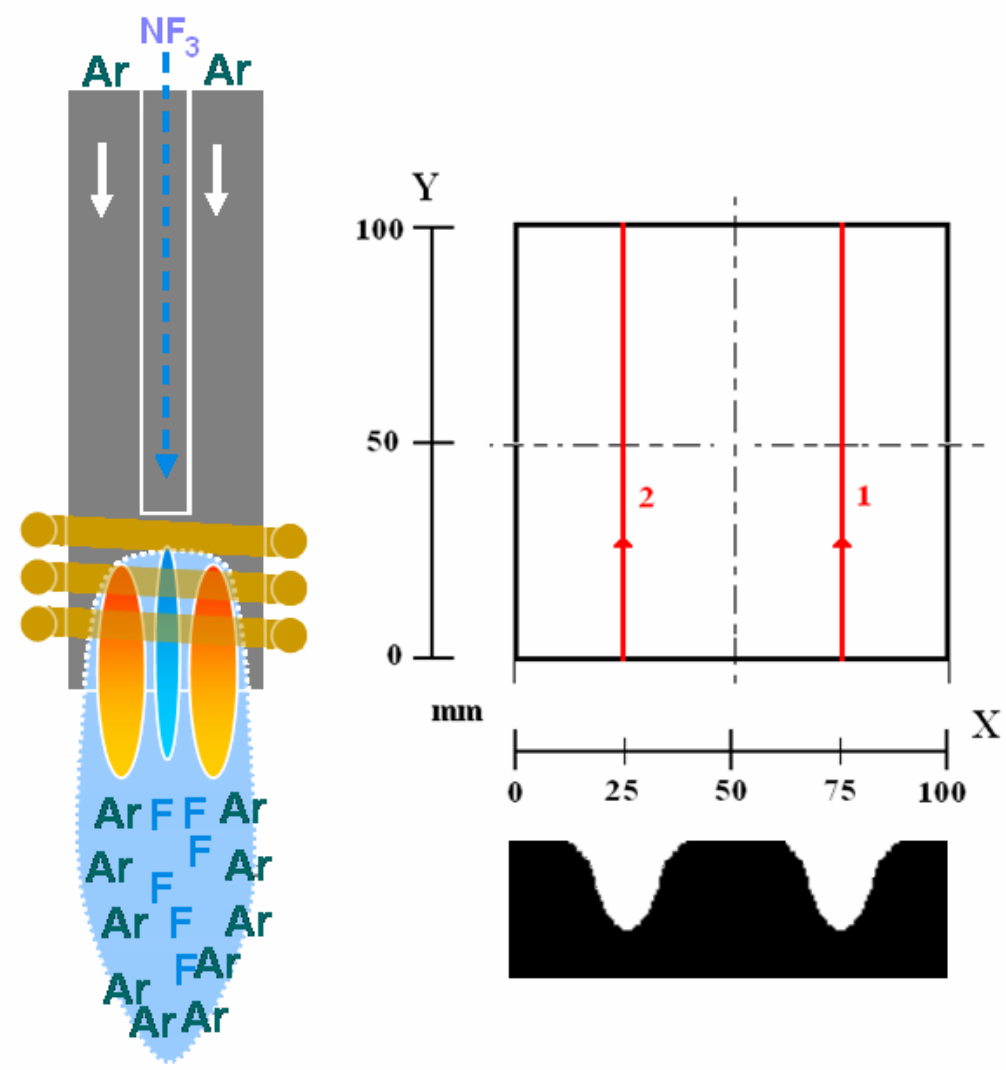

Figure 1 Principles of the RAPT process (see text). Right hand side: typical sample square geometry with the arrows indicating the torch pass direction. Scale of the depicted pseudogaussian trench: the horizontal (trough FWHM) of the order of 20 millimeters; depth, from few tens of nanometers up to a few microns. The distances from the sample centre are also indicated.

The initial choice of the reactive precursor has been $\mathrm{CF}_{4}$ (carbon tetra-fluoride). However, the lower energetic cost associated with the generation of $\mathrm{F}_{2}$ from $\mathrm{NF}_{3}(283 \mathrm{~kJ} / \mathrm{mol})$ looks more favorable with respect to $\mathrm{CF}_{4}(485 \mathrm{~kJ} / \mathrm{mol})$. Therefore, higher etch rates on $\mathrm{Si}, \mathrm{SiO}_{2}, \mathrm{SiC}$ and ULE are possible. Furthermore, the lower enthalpy of dissociation of $\mathrm{NF}_{3}$ implies a more efficient fluorine production per unit power $([\mathrm{F}] / \mathrm{W})$ making it possible to operate the process at reduced plasma power. The more complete $\mathrm{NF}_{3}$ breakdown generates byproducts that are readily scrubbed, lowering fluorinated emissions into the environment.

For large optics $\left(1\right.$ to $2 \mathrm{~m}^{2}$ ), it is difficult to set up and operate a pre-heating system capable to maintain a uniform temperature field over the entire sample surface. In the frame of the ongoing project ${ }^{[1]}$, several materials are considered: SiC in various forms, Zerodur ${ }^{\circledR}$, and $\mathrm{ULE}^{\circledR}$ and it is important to ascertain whether sample pre-heating can be avoided and under which circumstances.

This paper describes the first results obtained using $\mathrm{NF}_{3}$ on ULE. In view of the application of the process to the manufacturing of large optical surfaces, several important questions need consideration. This paper addresses the initial issues of etching ULE samples by keeping a good profile over extended distances $(1 \mathrm{~m})$ matching and possibly exceeding the process speed of competing technologies without pre-heating the substrates. Other factors considered are the influence of process parameters (the active specie fraction and the plasma power) on the material removal rate; the correlations between adjacent trenches upon subsequent plasma torch passes; 
the material removal rate upon multiple passes at the same location (e.g. trenches 'one on top of the other'). Additionally, some indications are given about the combined effects of gas specie concentration and input power on the sample surface temperature.

Several other questions are relevant for the fine tuning of the process: for example it is important to establish how to adapt to edge effects and enable the treatment of materials different than ULE at competitive removal rates. Also, the effects of the process on sub-surface damage originated by previous mechanical treatments (grinding) needs attention. A particularly important analysis is the study of the surface roughness Modifications as a function of the process parameters which may reveal re-deposition. All these aspects, and particularly the latter are the subject of the ongoing work and we will report on these as we progress.

\section{Results and Discussion}

The synopsis of the tests carried out is reported in the two tables in appendix A. The range of the trench depth varies from about $2.7 \mu \mathrm{m}$, down to about $100 \mathrm{~nm}$. The travel speed, the gas concentration and the plasma torch power where varied with the aim of attaining significant removal rates and therefore most of the following results are shown as a function of the travel speed. These data are obtained from the quantitative analysis of interferometer files, which report the differences between the surface prior and after the RAPT process (example in figure 2).

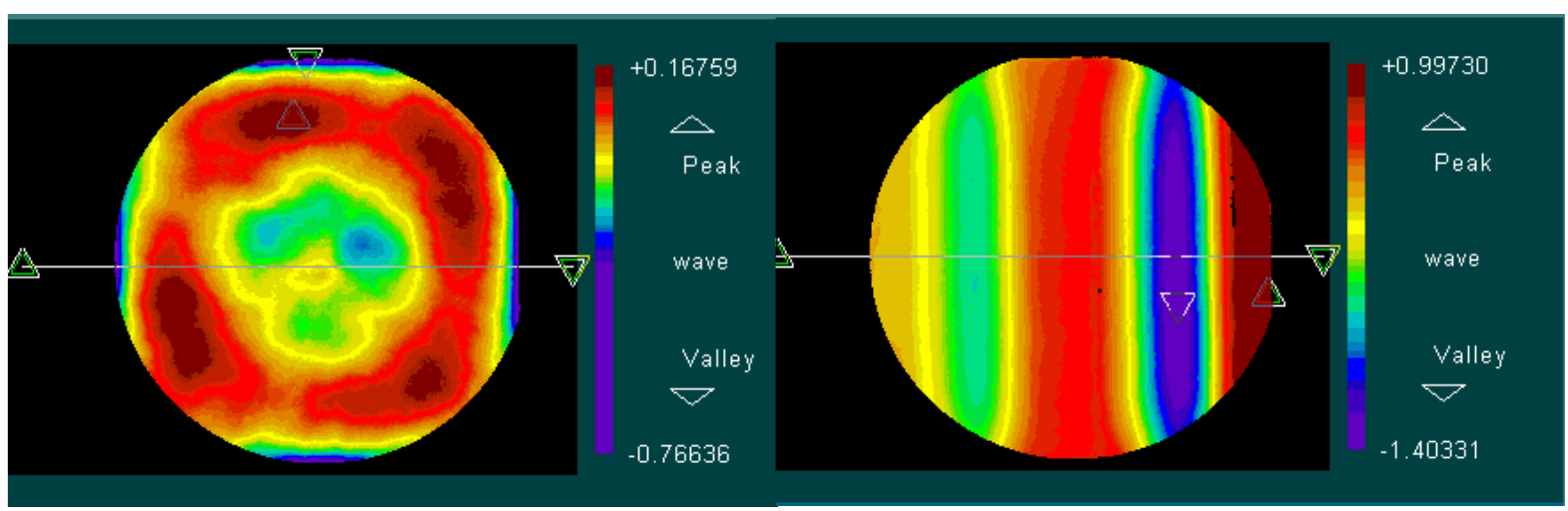

(a)

(b)

Figure 2 ULE sample 1 (a) before the treatment (b) after two parallel passes under different conditions (trenches 1 and 2, cf table 1 in appendix $A$.

An appreciation of the range of parameters can be gathered from figure 3, where the volumetric removal rate (defined in Appendix B and discussed in section 3.4) is shown for the two different $\mathrm{NF}_{3}$ concentrations with travel speed $(\mathrm{mm} / \mathrm{min})$ and plasma torch power $(\mathrm{W})$ as parameters. 


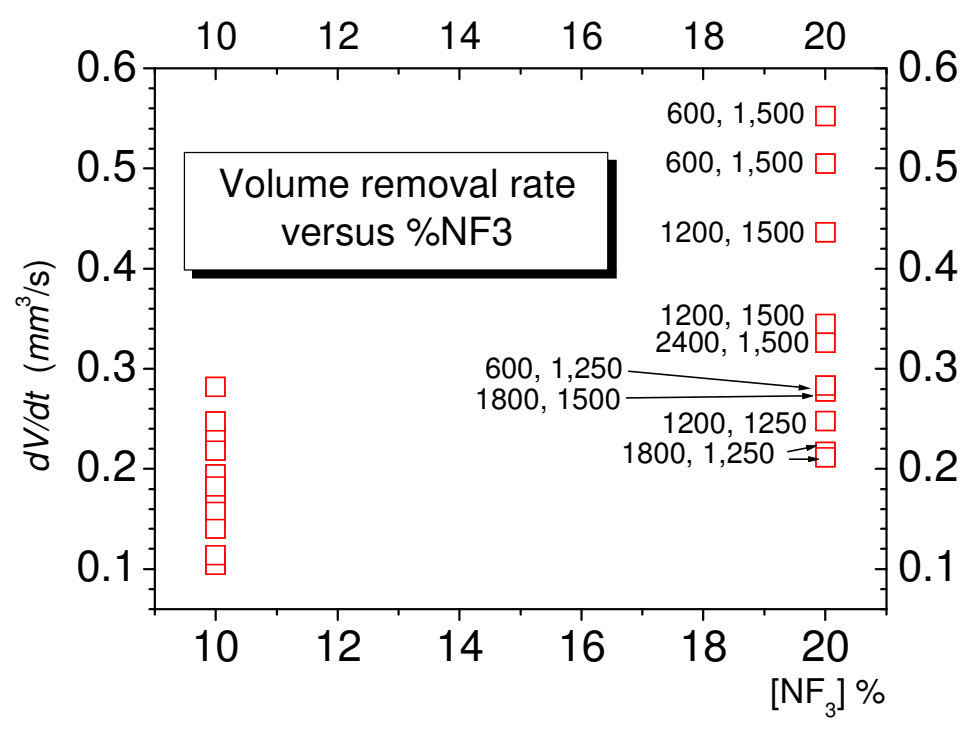

Figure 3 Volumetric removal rates as a function of gas concentration for different travel speed and plasma torch power (for clarity only the $20 \%$ data points are labelled with Travel speed $(\mathrm{mm} / \mathrm{min})$ and power $(\mathrm{W})$, in this order)

\subsection{Volumetric removal rates and trench depths}

The volumetric removal rate [cf Appendix B for all results and Appendix C for the computation], is shown as a function of the travel speed for the two values of the power employed in figure 4(a) and 4 (b) (1,250 $\mathrm{W}$ and $1,500 \mathrm{~W}$ respectively).

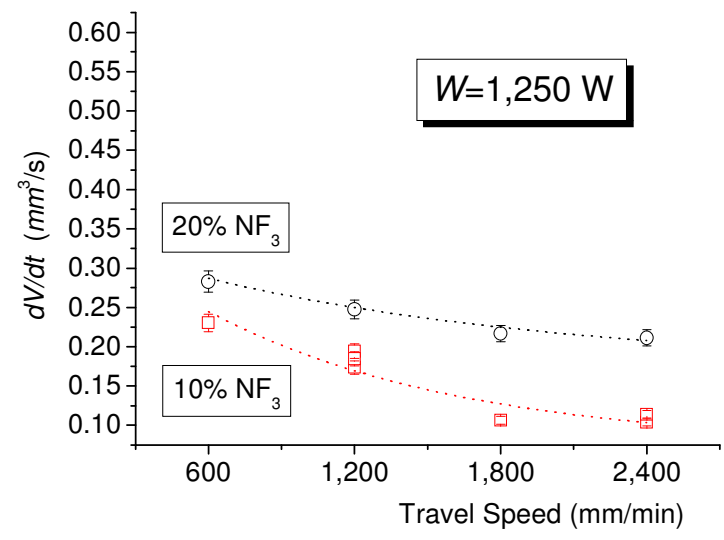

(a)

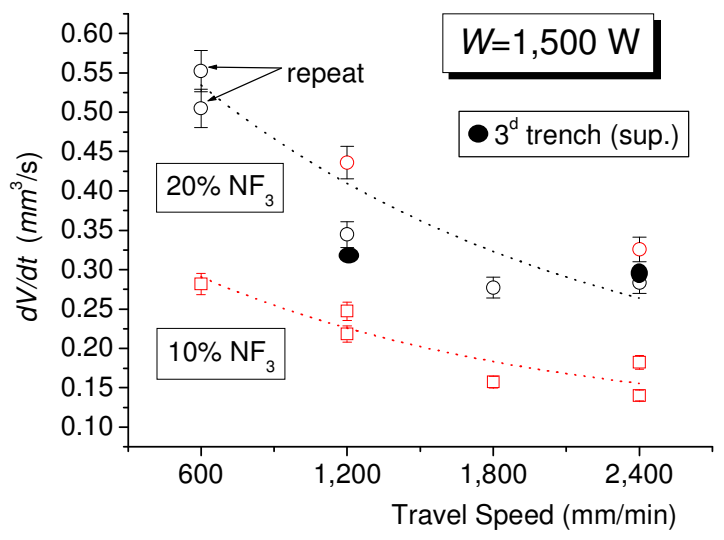

(b)

Figure 4 Volumetric removal rate as a function of travel speed at $10 \%$ and $20 \% \mathrm{NF}_{3}$ concentration (a) $1,250 \mathrm{~W}$ (b) $1,500 \mathrm{~W}$. 
As could have been expected, the rate decreases with the Travel Speed and an exponential decay seems appropriate. Similarly, one can show the dependency of the trench depths under the same conditions (figure 5).

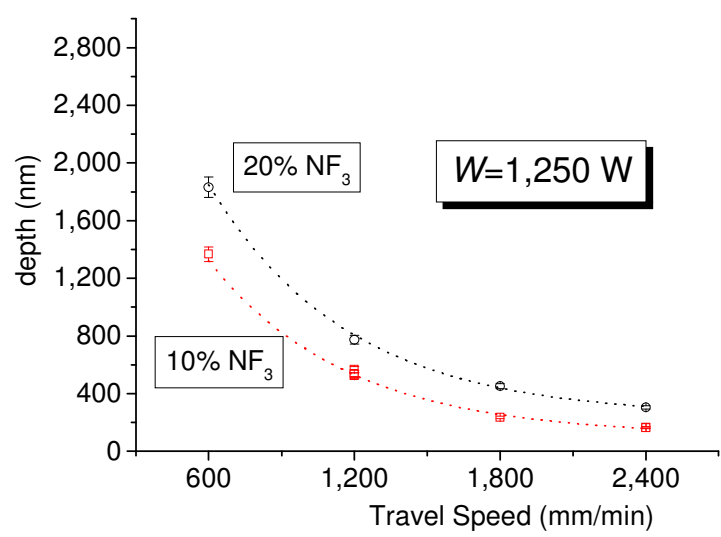

(a)

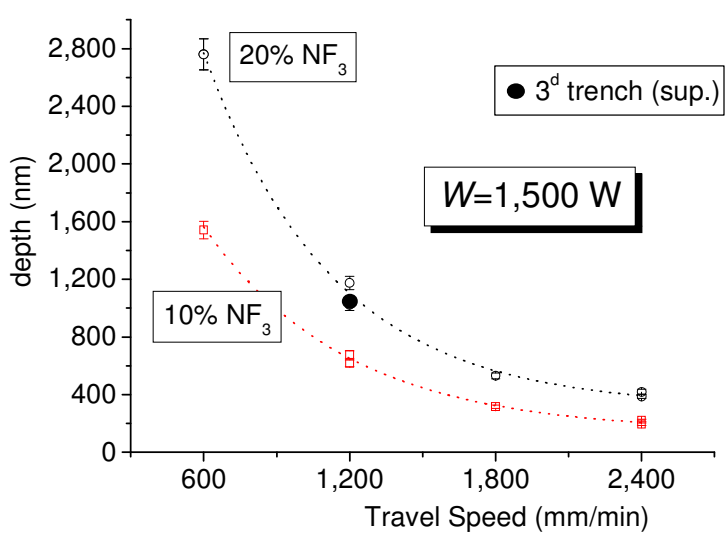

(b)

Figure 5 trench depth as a function of travel speed at $10 \%$ and $20 \% \mathrm{NF}_{3}$ concentration (a) 1,250 W (b) $1,500 \mathrm{~W}$.

In analogy with the volume rate, as expected, there is a decrease of the trench depth for increasing Travel Speed. The dependency seems exponential in both cases as shown in figure 5(a) and 5(b). The increase of the trench depth versus TS due to the doubling of the gas concentration can be compared with the one due to the power increase. To appreciate the relative variations, figure 6 reports the trench depth for the two powers and gas concentrations.

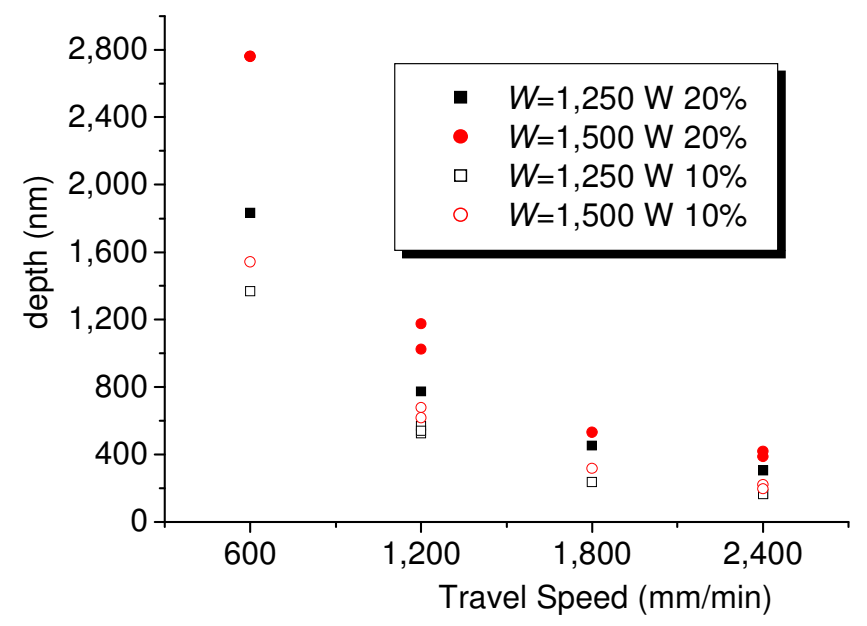

Figure 6 trench depth as a function of travel speed at $10 \%$ and $20 \% \mathrm{NF}_{3}$ concentration at the plasma torch power, 1,250 $\mathrm{W}$ and 1,500 $\mathrm{W}$. 
Clearly a doubling of the gas species is more effective than a mere $25 \%$ power increase. In fact, the range over which the gas concentration may vary is wider than the range over which the power may vary (on the one hand due to the minimum requirements for a given torch geometry in order to obtain and maintain a stable plasma; on the other, to the maximum power the system may be able to deliver for constructive and material limitations). For example, consider the point at $600 \mathrm{~mm} / \mathrm{min}$ : assuming in figure 6 that the increase of depth with power is linear (for simplicity), in order to get the same effect of the doubling of the gas by changing the power, one needs to raise the latter over $1,750 \mathrm{~W}$, which is beyond the capabilities of the plasma setup employed in these tests.

\subsection{The sample temperatures}

Once the torch enters the sample a progressively higher temperature of the latter is observed, which will depend on the travel speed, the plasma torch power and, in principle also on the gas concentration. An example of temperature traces is shown in figure 7.

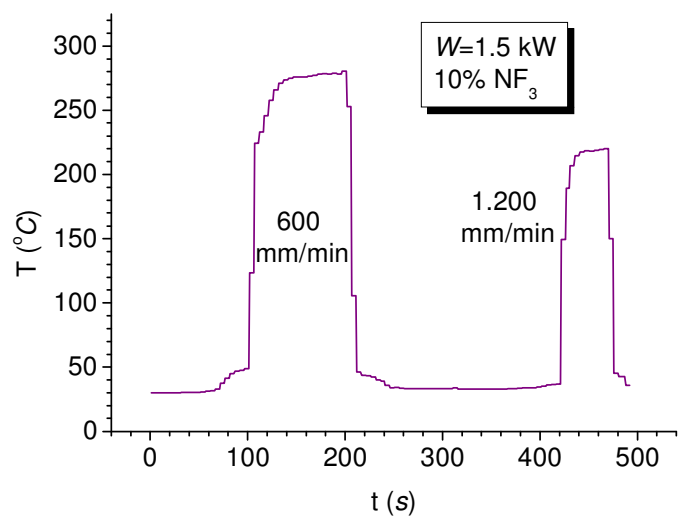

(a)

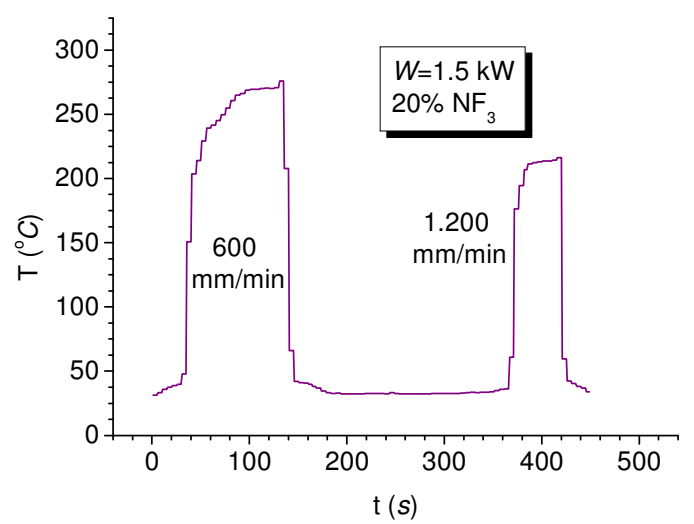

(b)

Figure 7 sample temperature trace at the two travel speeds 600 and $1,200 \mathrm{~mm} / \mathrm{min}$ (a) at $10 \%$ and (b) $20 \% \mathrm{NF}_{3}$ concentration. Power, $1,500 \mathrm{~W}$. The curves in each diagram indicate the entry and the exit of the plasma tool on the sample surface and correspond to trenches performed at different travel speed

The two pairs of traces do no differ significantly [The lower width of the peak on the right hand side is consequence of the higher travel speed]. One might think that a doubled gas concentration could lead to differential heating (the other parameters being held constant). In figure 8 the maximum sample temperature, taken when the plasma plume is slightly beyond the sample midplane (cross-section) is reported as a function of the travel speed for the two concentrations and plasma powers. The extreme of the maximum sample surface temperatures within the travel speed range 600 to $2,400 \mathrm{~mm} / \mathrm{min}$, are $120{ }^{\circ} \mathrm{C}$ to $220{ }^{\circ} \mathrm{C}$ (at $1,250 \mathrm{~W}$ ) and $170^{\circ} \mathrm{C}$ to $280^{\circ} \mathrm{C}$ (at $1,500 \mathrm{~W})$. 


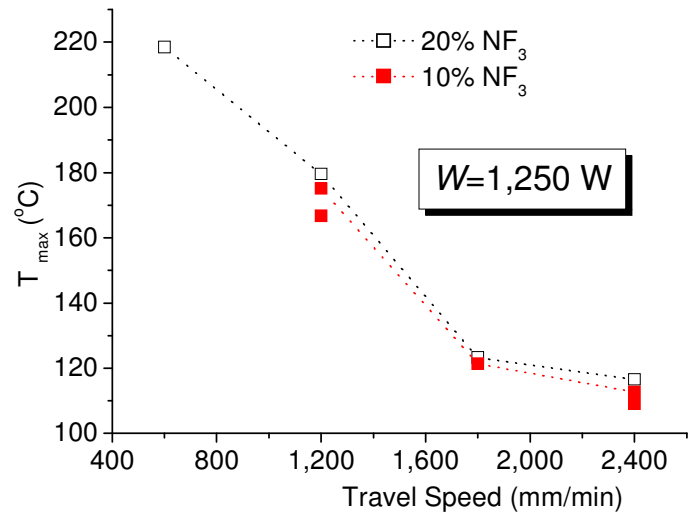

(a)

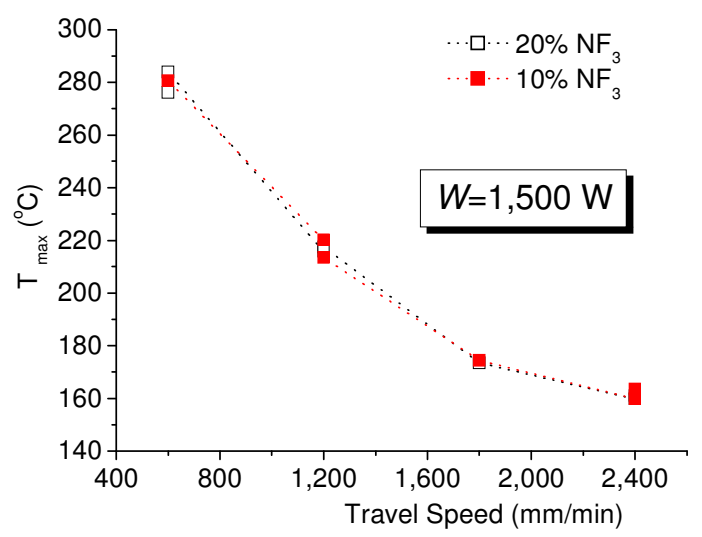

(b)

Figure 8 sample maximum temperature as a function of travel speed at $10 \%$ and $20 \% \mathrm{NF}_{3}$ concentration and two values of the plasma torch power (a) 1,250 W and (b) 1,500 W.

Clearly, there isn't any correlation between the gas concentration and the maximum temperature of the sample surfaces. Note that in the case of $1,250 \mathrm{~W}$, the two points plotted at $1,200 \mathrm{~mm} / \mathrm{min}$ correspond to two trenches performed in different sequence: the lowest of the two pertains to a 'repeated' trench, e.g. a trench superimposed to the previous case (whose temperature however is not available), thus there is a justification for 'some' difference due to the different initial conditions: the repeated trench is performed on a pre-existing trench. A similar situation occurs at $2,400 \mathrm{~mm} / \mathrm{min}$ where now the temperatures of trench 2 and the superimposed trench 3 are both available: the latter is slightly higher. The opposite occurs at $1,500 \mathrm{~W}$ where the latter trench shows a lower temperature. Therefore, based on these few thermal data, it is not possible to conclude whether the superimposed trench leads to a higher or lower temperature and an ameliorated temperature measurement system is under development.

However, it is possible to conclude that within the limits of the instrumental sensitivity the effects of the gas concentration on the temperature is negligible and therefore the major actor in the samples thermal state is the plasma power (and test to determine heat release of thermochemical origin may be excluded for the ULE samples).

Also, it is possible to note that at the highest speed $(2,400 \mathrm{~mm} / \mathrm{min})$ and the lower of the two powers $(1,250 \mathrm{~W})$ the process is still capable of removing layers of $\sim 160 \mathrm{~nm}$, with local maximum temperature not exceeding of $\sim 110^{\circ} \mathrm{C}$.

\subsection{Adjacent and overlapped trenches}

With the exception of one case, the tests were performed by keeping the distances between trenches $(50 \mathrm{~mm})$ to values which are more than twice the typical FWHM or of the lateral 'tool size' $(\sim 40 \mathrm{~mm})$. The idea was to study trenches which are not interfering one with the other. However, as the tool is intended to etch extended surfaces, it is interesting to characterize trenches which can superimpose, in order to be able to optimize the tool passes during the process of those. An example of adjacent trenches is reported in figure 9, where two trenches from sample 5 were produced with a distance between trenches reduced from 50 to $20 \mathrm{~mm}$. The first two curves from above are the individual peaks; the third (bottom) is the resulting trench cross section. Note that the dotted line in the overlapping region (c) was drawn to compare the trench features with part (a) 


\subsection{Material removal rates}

The values computed for all the samples are reported for two gas concentrations and two powers in the tables in Appendix B. Because of edge effects, where possible, an attempt has been made to select the portions of the longitudinal trench where a 'reasonably' flat profile was found.

Without considering superimposed trenches, the highest value of the steady state material removal rate, $0.505( \pm 0.024) \mathrm{mm}^{3} / \mathrm{s}$, is attained at $600 \mathrm{~mm} / \mathrm{min}$; the lowest, still a respectable $0.107 \mathrm{~mm}^{3} / \mathrm{s}$, at $1,800 \mathrm{~mm} / \mathrm{min}$.

Clearly, when operating with more extended surfaces, the edge effects will need to be addressed with appropriate algorithms for the control of the dwelling time in order to regulate the heat transfer to the substrates.

\subsection{Other correlations}

So far the correlation between the power and the active gas flow on the width of the trenches has been neglected. With respect to the increase in gas flow, the width does not seem very much influenced by the doubling of the gas flow, although a more extended database would be necessary to confirm this observation.

It is not possible to ascertain whether the variations in the removal upon superimposed trenches are accompanied by variations on the FWHM: this would help predict whether in the same conditions, the RAPT tool becomes finer or coarser upon subsequent passes. In absence of further data, we will consider the width as 'practically unchanged'. Future estimation of this parameter will be attempted as it will permit to determine the number of passes necessary to etch a given surface uniformly.

\section{Conclusions and ongoing work}

The RAPT, a new atom plasma etching process operating at atmospheric pressure, has been successfully applied to $\mathrm{ULE}^{\circledR}$ glass samples without the need to pre-heat the surfaces. The removal rates appear very competitive with respect to other processes like IBF. The travel speeds (TS) employed in these tests are not necessarily the highest attainable with acceptable removal rates. In other words, tests to increase TS and attain nominally 'zero removal' have not been performed yet and the attainment of trench depths of $110 \mathrm{~nm}$ or less at considerably higher TS $(2,400 \mathrm{~mm} / \mathrm{min})$ indicates that 'finer tuning' with smaller depths is attainable. In general, it is possible to match and exceed the process speed of competing technologies: in this work 0.55 $\mathrm{mm}^{3} / \mathrm{s}$, against the $0.019 \mathrm{~mm}^{3} / \mathrm{s}$ reported for the only other atmospheric pressure plasma process known (Nikon, even if the comparison should be based on common substrate compositions).

An increase in the concentration of the active specie flow increases the material removal as does the increase of the plasma torch power, but the first provides a broader range of variability for the removal rates.

Adjacent trenches kept at the nominal $50 \mathrm{~mm}$ distances do not seem to influence one another, in that the visible portion of the trench profile maintains a Gaussian profile. Quantitative evaluation of the surface state (roughness) prior and post-process has not been performed yet and further surface analysis is under way. In particular, an understanding of the possible degradation of the surface roughness through the RAPT process is part of this work.

The temperature records do not depend on the gas concentration, therefore, the in-principle possibility of crossed thermo-chemical effects is ruled out. The maximum sample temperatures never exceeded the $220{ }^{\circ} \mathrm{C}$ during the treatment with the longest dwelling time. Different materials will be tested against the possibility of etching without or limited sample pre-heating and further tests on $\mathrm{SiC}$ surface are scheduled. 


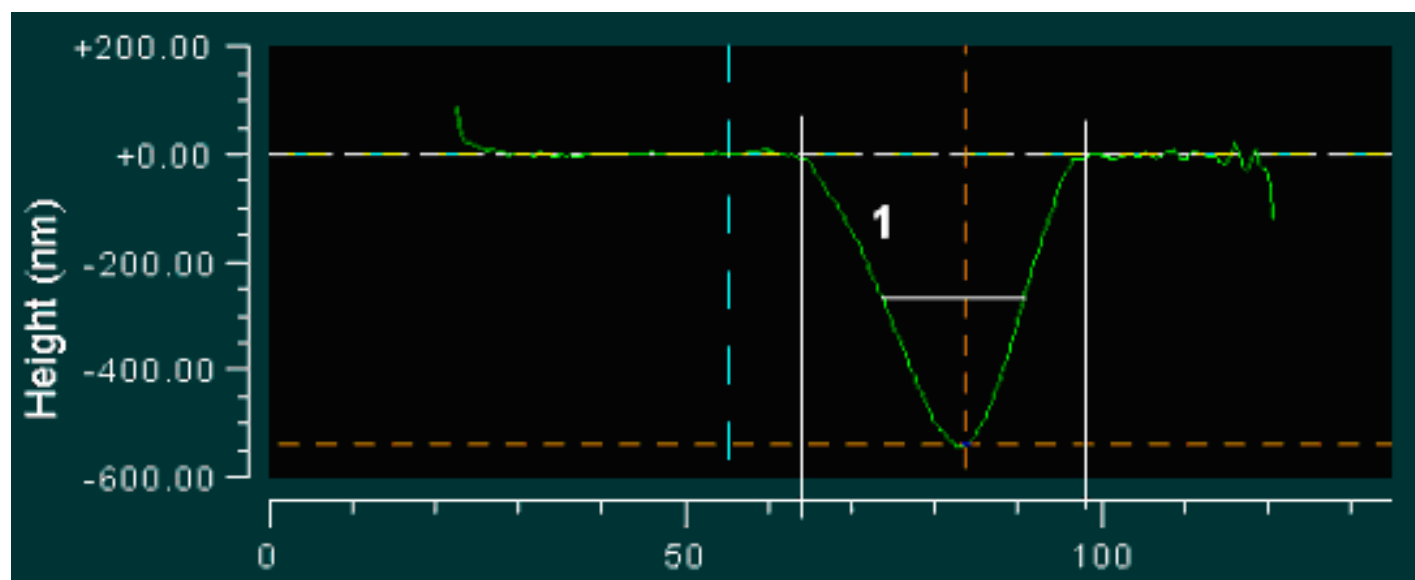

(a)

Distance $(\mathrm{mm})$
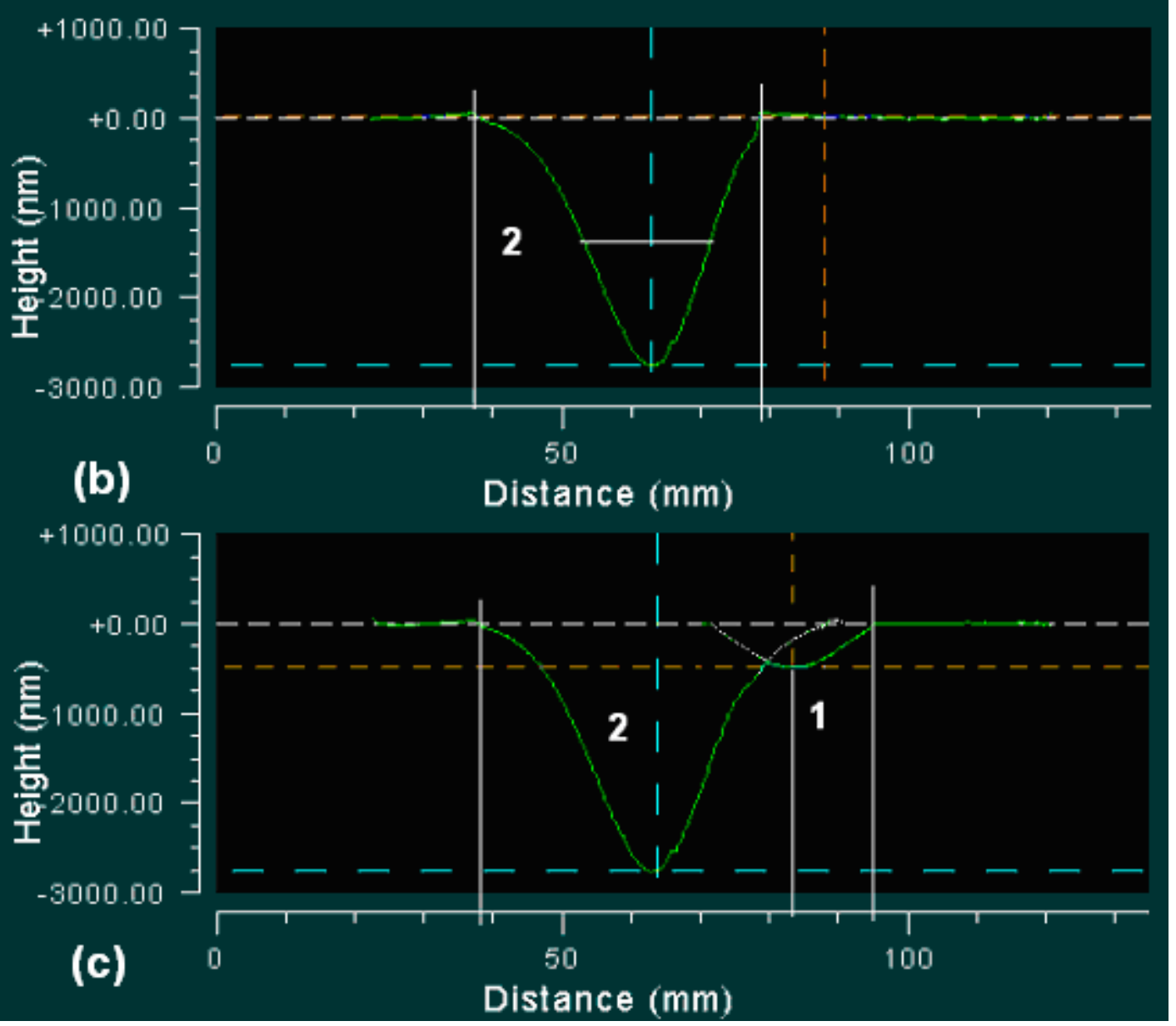

Figure 9 adjacent trenches due to first and second pass. From above, trenches obtained (1) with Travel Speed 1200, at 10\% NF 3 and 1,250 W and (2) Travel speed 600, at 20\% $\mathrm{NF}_{3}$ and 1,500 W Bottom, partially overlapping trenches from first and second pass. For cross-check purposes, the dotted line in the overlapping region (c) was drawn to compare the trench features with (a) 


\section{Appendix A - Experimental set up}

The plasma source consists of an ICP torch and matching network enclosed in a chamber within a double encasing, equipped with safety interlocks and gas exhaust controls and a gas scrubber. A two axis motion stage, capable of displacements of $320 \mathrm{~mm}$ in both $\mathrm{X}$ and $\mathrm{Y}$ directions, moves the samples beneath the plasma torch, see figure 1. The ICP torch is made of three coaxial quartz tubes [1] and operated at a frequency $f=27.12 \mathrm{MHz}$ and power typically $\mathrm{W}=1.25$ to $1.5 \mathrm{~kW}$. The plasma gas, $A r$, is immitted through the external tube (18 $\mathrm{mm}$ diameter) with a tangential inlet at a flow of 15,000 sccm. Tests have been performed using $N F_{3}$ on ULE test samples (100x100x20 $\mathrm{mm}^{3}$ ). The 'auxiliary' gas, also $A r$, is immitted through the intermediate tubing at a rate of 300 $\mathrm{sccm}$, whereas the active specie $\mathrm{NF}_{3}$ is kept at a flow of $1,000 \mathrm{sccm}\left(1 \mathrm{sccm}=10^{-3} \mathrm{slm}\right)$.

A pyrometer yields the spatial average of the sample surface temperature directly beneath the torch, over a spot of diameter $20 \mathrm{~mm}$. When the plasma plume is located at distances below 20 $\mathrm{mm}$ from the sample edge, the averages include points pertaining to the sample holder and thus yield un-calibrated readings. Nevertheless, comparative features can be extracted from the temperature-time profiles taken from measurements performed in identical geometries when the spot falls entirely on the sample. In order to visualize the differences in surface profiles induced by the plasma, pre- and post -process analysis is performed with a range of techniques. Interferometry is used and results of measurements are shown here, taken with a Zygo interferometer ('GPI') before and after the RAPT process.

In the case of ULE, the tests were made to determine an operational window based on the variation of three quantities: travel speed, plasma torch power and active specie concentration. The Travel speed was unknown but it had to be comparable and possibly beyond the limits of competing technologies. As shown below, when trench depth and volumetric removal rate are considered this has been the case. The tests geometry is displayed in figure 1and the typical interferometric aspect of the sample surface after the process is shown in figure 2 where two trenches of pseudo-gaussian cross section are visible [It should be noted that the three dimensional picture in figure $1 \mathrm{~b}$ appears circular according to the input optics of the interferometer, with diameter $100 \mathrm{~mm}$ ]. 


\section{Appendix B - ULE Tests and trenches synopsis}

The depths reported are taken at the sample mid section and are computed as differences between the original profile and subsequent passes.

Table 1. Tests series (I)

\begin{tabular}{|c|c|c|c|c|c|c|c|c|c|}
\hline ULE & $\begin{array}{c}\mathrm{P} \\
(*)\end{array}$ & $\begin{array}{c}W \\
(W)\end{array}$ & $\begin{array}{l}\mathrm{NF}_{3} \\
\%\end{array}$ & $\begin{array}{c}\mathrm{TS} \\
(\mathrm{mm} / \\
\mathrm{min})\end{array}$ & $\begin{array}{c}\mathrm{a} \\
\mathrm{mm}\end{array}$ & $\begin{array}{ll}\operatorname{Max} & \mathrm{T} \\
\left({ }^{\circ} \mathrm{C}\right) & \end{array}$ & $\begin{array}{l}\text { Depth } \\
(\mathrm{nm})\end{array}$ & FWHM (mm) & $\dot{\boldsymbol{V}}\left(\mathrm{mm}^{3} / \mathrm{s}\right)$ \\
\hline 1 & $\begin{array}{l}1 \\
2 \\
3 \mathrm{r}) \\
\end{array}$ & $\begin{array}{l}1,250 \\
1,250\end{array}$ & $\begin{array}{l}10 \\
10\end{array}$ & $\begin{array}{l}600 \\
1,200\end{array}$ & $\begin{array}{l}- \\
50\end{array}$ & $\begin{array}{l}- \\
- \\
167.4\end{array}$ & $\begin{array}{l}1367 \\
567 \\
+524 \\
\end{array}$ & $\begin{array}{l}16.86 \\
17.14 \\
16.57 \\
\end{array}$ & $\begin{array}{l}0.230(11) \\
0.194(9) \\
0.174(8)\end{array}$ \\
\hline 2 & $\begin{array}{l}1 \\
2 \\
3 \mathrm{r}) \\
\end{array}$ & $\begin{array}{l}1,500 \\
1,500\end{array}$ & $\begin{array}{l}10 \\
10\end{array}$ & $\begin{array}{l}600 \\
1,200\end{array}$ & $\begin{array}{l}- \\
50\end{array}$ & $\begin{array}{l}276.0 \\
216.3 \\
213.6 \\
\end{array}$ & $\begin{array}{l}1541 \\
676 \\
+616 \\
\end{array}$ & $\begin{array}{l}18.29 \\
18.29 \\
17.71 \\
\end{array}$ & $\begin{array}{l}0.282(14) \\
0.247(12) \\
0.218(10) \\
\end{array}$ \\
\hline 3 & $\begin{array}{l}1 \\
2 \\
3 \mathrm{r}) \\
\end{array}$ & $\begin{array}{l}1,500 \\
1,500\end{array}$ & $\begin{array}{l}20 \\
20\end{array}$ & $\begin{array}{l}600 \\
1,200\end{array}$ & $\begin{array}{l}- \\
50\end{array}$ & $\begin{array}{l}280.3 \\
220.3 \\
213.4 \\
\end{array}$ & $\begin{array}{r}2761 \\
1174 \\
+1022 \\
\end{array}$ & $\begin{array}{l}20.0 \\
18.57 \\
16.86 \\
\end{array}$ & $\begin{array}{l}0.552(26) \\
0.436(21) \\
0.345(17) \\
\end{array}$ \\
\hline 4 & $\begin{array}{l}1 \\
2 \\
\end{array}$ & $\begin{array}{l}1,250 \\
1,250\end{array}$ & $\begin{array}{l}20 \\
20 \\
\end{array}$ & $\begin{array}{l}600 \\
1,200 \\
\end{array}$ & $\begin{array}{l}- \\
50 \\
\end{array}$ & $\begin{array}{l}218.5 \\
179.4 \\
\end{array}$ & $\begin{array}{l}1832 \\
774 \\
\end{array}$ & $\begin{array}{l}15.43 \\
16.0 \\
\end{array}$ & $\begin{array}{l}0.283(14) \\
0.248(12)\end{array}$ \\
\hline 5 & $\begin{array}{l}1 \\
2 \\
1 \mathrm{~s}\end{array}$ & $\begin{array}{l}1,250 \\
1,500\end{array}$ & $\begin{array}{l}10 \\
20\end{array}$ & $\begin{array}{l}1,200 \\
600\end{array}$ & $\begin{array}{l}- \\
20\end{array}$ & $\begin{array}{l}175.2 \\
284.2\end{array}$ & $\begin{array}{l}539 \\
2760 \\
\sim 500\end{array}$ & $\begin{array}{l}17.14 \\
18.29 \\
14.29(1)\end{array}$ & $\begin{array}{l}0.185(9) \\
0.505(24)\end{array}$ \\
\hline
\end{tabular}


Table 2. Tests series (II)

\begin{tabular}{|c|c|c|c|c|c|c|c|c|c|}
\hline ULE & $\begin{array}{c}\mathrm{P} \\
(*)\end{array}$ & $\begin{array}{l}\text { W } \\
(W)\end{array}$ & $\begin{array}{l}\mathrm{NF}_{3} \\
\%\end{array}$ & $\begin{array}{c}\mathrm{TS} \\
(\mathrm{mm} / \\
\mathrm{min})\end{array}$ & $\begin{array}{c}\mathrm{a} \\
\mathrm{mm}\end{array}$ & $\begin{array}{l}\text { T Max } \\
\left({ }^{\circ} \mathrm{C}\right)\end{array}$ & $\begin{array}{l}\text { Depth } \\
\text { d nm }\end{array}$ & FWHM mm & $\begin{array}{l}\dot{\boldsymbol{V}} \\
\mathrm{mm}^{3} / \mathrm{s}\end{array}$ \\
\hline $5 b$ & $\begin{array}{l}1 \\
2 \\
3 r)\end{array}$ & $\begin{array}{l}1,250 \\
1,250\end{array}$ & $\begin{array}{l}10 \\
10\end{array}$ & $\begin{array}{l}1,800 \\
2,400\end{array}$ & 50 & $\begin{array}{r}121.3 \\
112.7 \\
+109 \\
\end{array}$ & $\begin{array}{l}234.8 \\
163 \\
165.6 \\
\end{array}$ & $\begin{array}{l}15.14 \\
17.43 \\
15.71 \\
\end{array}$ & $\begin{array}{l}0.107(5) \\
0.114(5) \\
0.104(5)\end{array}$ \\
\hline $2 b$ & $\begin{array}{l}1 \\
2 \\
3 r) \\
\end{array}$ & $\begin{array}{l}1,500 \\
1,500\end{array}$ & $\begin{array}{l}10 \\
10\end{array}$ & $\begin{array}{l}1,800 \\
2,400\end{array}$ & 50 & $\begin{array}{l}174.4 \\
163.6 \\
+159.9 \\
\end{array}$ & $\begin{array}{l}316.2 \\
194.6 \\
221.7 \\
\end{array}$ & $\begin{array}{l}16.57 \\
18 \\
20.57 \\
\end{array}$ & $\begin{array}{l}0.157(8) \\
0.140(7) \\
0.182(9) \\
\end{array}$ \\
\hline $3 b$ & $\begin{array}{l}1 \\
2 \\
3 \mathrm{r})\end{array}$ & $\begin{array}{l}1,500 \\
1,500\end{array}$ & $\begin{array}{l}20 \\
20\end{array}$ & $\begin{array}{l}1,800 \\
2,400\end{array}$ & 50 & $\begin{array}{r}173.5 \\
159.8 \\
+161 \\
\end{array}$ & $\begin{array}{l}530 \\
387 \\
419 \\
\end{array}$ & $\begin{array}{l}17.43 \\
18.29 \\
19.43 \\
\end{array}$ & $\begin{array}{l}0.139(7) \\
0.283(14) \\
0.326(16)\end{array}$ \\
\hline $4 b$ & $\begin{array}{l}1 \\
2\end{array}$ & $\begin{array}{l}1,250 \\
1,250\end{array}$ & $\begin{array}{l}20 \\
20\end{array}$ & $\begin{array}{l}1,800 \\
2,400\end{array}$ & 50 & $\begin{array}{l}123.2 \\
116.5\end{array}$ & $\begin{array}{l}451.6 \\
303.2\end{array}$ & $\begin{array}{l}16 \\
17.43\end{array}$ & $\begin{array}{l}0.217(10) \\
0.211(10)\end{array}$ \\
\hline
\end{tabular}

\section{LEGEND}

$a=$ Distance between trenches, $\mathrm{mm} ; T S=$ Travel Speed $(\mathrm{mm} / \mathrm{min}), w$ width at base, FWHM= Full width at Half Maximum; $L=$ length of the flat portion of trench. In parentheses is included a 'reasonably flat' portion (see text); " $+\mathrm{xxx}$ " means incremental due to repeated pass. " $r$ " = pass repeated on top of preceding with same parameters; " $s "=$ superposition between adjacent trenches.

\section{Appendix C - Material Removal}

By taking the difference of profiles depths $(\mathrm{nm})$ it is possible to estimate the material removal rate. Using the Gaussian approximation for the transverse profiles, multiplying the depth of the trench $d$ (in $\mathrm{nm}$ ) (1) by half the width of the trench $w$ (the FWHM of the Gaussian transverse profile, in $\mathrm{mm}$ ); and (2) by the longitudinal path distance $L$ (in $\mathrm{mm}$ ); dividing the result by the time interval $\tau$ (s) to cover the distance $L, \tau=L / \mathrm{v}$ (where $\mathrm{v}$ is the travel speed TS), the volumetric $\left(\mathrm{mm}^{3} / \mathrm{s}\right)$ and mass removal rate $(\mathrm{g} / \mathrm{s})$ may be estimated:

$$
\begin{aligned}
& \dot{V}=\frac{L d w / 2}{\tau}=\frac{L d w / 2}{L / \mathrm{v}}=d \cdot w \cdot \mathrm{v} / 2 \\
& (w=F W H M) \\
& \dot{m}=\rho \cdot \dot{V}=2.21 \cdot 10^{-3}\left(\mathrm{~g} / \mathrm{mm}^{3}\right) \cdot \dot{V}\left(\mathrm{~mm}^{3} / \mathrm{s}\right)
\end{aligned}
$$

For the latter, the uncertainty of the density of ULE $\left(2.21 \cdot 10^{3} \mathrm{Kg} \mathrm{m}^{-3} \pm 0.5 \%\right)$ should be incorporated together with the uncertainties on all the linear quantities, assumed to be $3.88 \%$ for the scatter on the depth of the profile; and $5.7 \%$ for the transversal trench. However, as the 
density is estimated at ambient temperature, we prefer to quote the results in the main text as volumetric removal rates. Note that the hypothesis used in the computation is that a triangular shape approximates the trench cross section, with base=FWHM and height taken as the trench depth.

\section{References}

1. Walker, D., Shore P., Ultra Precision Surfaces - a New Paradigm, Basic Technology Case for Support, 2003.

2. Carr, J., RAPT Industries Inc., Patent PCT/US02/02507 International Publication number WO 02/060828. 2002.

3. Flamm, D.L., Pure and Applied Chemistry, 1990, 62,1710.

4. Manos, D.M., Flamm, D.L., in Plasma etching, an introduction (Eds: O. Auciello, Flamm, D.L.), Academic Press, Boston, 1989.

5. Suzuki, K., Itabashi, N, Pure and Applied Chemistry, 1996, 68, 1011.

6. Mirkarimi, P.B., Baker, S L, Montcalm, C, Folta, J A, Applied Optics, 2001, 40, 62.

7. http://www.newportglass.com/amscergl.htm, Material safety sheet. 2005, Newport Glass.

8. Mirkarimi, P.B., Baker, S L, Montcalm C, Folta, J A, Applied Optics, 2001, 40, 62.

9. Schindler, A., T. Haensel, D. Flamm, A. Nickel, H. J. Thomas, F. Bigl. Precision Science and Technology for Perfect Surfaces, Tokyo: The Japanese Society for Precision Engineering, 1999.

10. Adams, D.P., Vasile, M J, Krishnan, A S M, Precision Engineering, 2000, 24, 347.

11. Mast, T.S., Nelson, J E, Sommargren, G E, Segment Fab - SPIE 2000, 2000.

12. Walker, D.D., Doel, A P, Bingham, R G, Brooks, D, King, A M, , Optical Science Laboratory, University College London (D D Walker, Study Co-ordinator), UK National Physical Laboratory, QinetiQ Ltd, Zeeko Ltd. 2002, 1.

13. Nikon, 2005, http://www.nikon.co.jp/main/eng/portfolio/about/technology/nikon_technology/plasma_c vm_e/index.htm.

14. Gailly, P., AMTT Program, Seibersdorf, Microstructure evolution of after ion beam bombardment. 2000, Centre Spatial de Liege - Universite de Liege. p. 1-14. 